\title{
Selected lines of Aedes aegypti with persistently distorted sex ratios
}

\author{
KOFI OHENE OWUSU-DAAKU†, ROGER JOHN WOOD* \& RONALD DEREK BUTLER \\ School of Biological Sciences, University of Manchester, Stopford Building, Oxford Road, Manchester M13 9PT, U.K.
}

\begin{abstract}
A breeding scheme to isolate $\mathrm{X}$ chromosomes sensitive to drive by the $\mathrm{T} 8$ (Trinidad) $\mathrm{Y}$ chromosome of Aedes aegypti (the $M D$ haplotype) is reported. Crosses with an Australian strain Th.I (Thursday Island) revealed not only sensitive and resistant $\mathrm{X}$ chromosomes but also some with the capacity to drive against the T8 Y chromosome. Four strains were created in which sex ratio was male-distorted (28-36 per cent $\$)$ for 10 generations, with no regression towards sexual parity. The proportion of females varied significantly between generations in each of the four strains. Further selection produced strains with normal sex ratios, capable of generating fewer than 15 per cent $q$ on outcrossing to T8 males.
\end{abstract}

Keywords: Aedes aegypti, meiotic drive, mosquito, sex ratio.

\section{Introduction}

The meiotic drive gene $D$ in the mosquito Aedes aegypti is closely linked to the male-determining gene (region) $M$ on the $\mathrm{Y}$ chromosome (Hickey \& Craig, 1966a) and shows a holandric mode of inheritance (Craig et al., 1960; Wood, 1961). Studies on a strain from Trinidad have revealed different degrees of drive according to the sensitivity of the $\mathrm{X}$ chromosome with which the Trinidad $M D \mathrm{Y}$ chromosome is associated during male meiosis (Wood, 1976; Wood \& Newton, 1977). Overall, there is a consistent deficit of females, giving a sex ratio of $0.40-0.43$ in various substrains of Trinidad origin, which has been observed over more than 30 years of laboratory culture, and is largely independent of prezygotic or postzygotic differential mortality (Wood \& Newton, 1991). During this period, the Trinidad strain and its derivatives T30 and T8 have been used as tester stocks to identify and quantify sensitivity to $M D$ in other strains. The most consistently sensitive $\mathrm{X}$ chromosomes identified were found in a strain collected on the island of Chipei, located in the Pescadores group between Taiwan and the Chinese mainland. $F_{1}$ males carrying a Chipei $\mathrm{X}$ chromosome coupled with a Trinidadderived Y chromosome consistently yielded $<15$ per cent $q$ (Wood, 1976; Wood \& Ouda, 1987).

\footnotetext{
*Correspondence. E-mail: biowill@fs1.ge.man.ac.uk

†Present address: Department of Biological Sciences, University of Science \& Technology, Kumasi, Ghana.
}

In the meiosis of such males, yielding a sex ratio of 3.8 per cent , Newton et al. (1976) observed fragmentation of the sex chromosomes at or before diplotene, the majority of breaks being on the $\mathrm{X}$ chromosome. The density of spermatozoa arising from such cells was correspondingly reduced, and among the survivors the DNA content could be abnormally high, up to the 4C level (Newton et al., 1978). Many of the spermatozoa appeared morphologically abnormal. Recent studies have been carried out to investigate the abnormalities by electron microscopy (Owusu-Daaku, 1994). The present study was in support of that work, aimed at recreating the crosses of Newton et al. (1976, 1978). The Chipei strain was no longer under culture and fresh supplies could not be obtained, so it was necessary to produce a highly sensitive strain by selection. Crosses revealed that the most sensitive strains available were two from the north-east coast of Australia-Thursday Island (Th.I) and Townsville (Twn) (see also Tesfamariam, 1993). A breeding scheme was used to produce a series of sensitive strains of two types: (i) the ThST strains with the $D$ gene; and (ii) the Syn strains and Syn (s) strains without the $D$ gene. This is the work reported here.

\section{Materials and methods}

\section{Strains}

Three strains were involved in the experiment to be described. 
Trinidad-8(T8) Derived from a strain collected on this Caribbean island in 1953, T8 was isolated from a single-pair mating by Wood (1968). The males carry $\mathrm{Y}$ chromosomes that drive against sensitive $\mathrm{X}$ chromosomes of a number of other strains. The Y chromosomes of this and other Trinidad-derived strains also drive against some of their own $\mathrm{X}$ chromosomes, so that the sex ratio is mildly distorted (40-43 per cent \%). Stated in the simplest terms the $\mathrm{X}$ chromosomes of $\mathrm{T} 8$ are either $\mathrm{X}^{\mathrm{R}}$ (resistant to $\mathrm{T} 8 \mathrm{Y}$ drive) or $\mathrm{X}^{\mathrm{S}}$ (sensitive to $\mathrm{T} 8 \mathrm{Y}$ drive), although there are degrees of sensitivity recognized $\left(\mathrm{X}^{\mathrm{S1}}-\mathrm{X}^{\mathrm{S6}}\right)$ and also drive of $\mathrm{X}$ against $\mathrm{Y}$ in a small minority of males (Wood, 1976; Suguna et al., 1977).

Triple-marked (TPM) This multiple marker strain (also known as RED) was supplied by $\operatorname{Dr} \mathbf{L}$. Munstermann. It carries the markers red eye (re) on chromosome I, spot abdomen (s) on chromosome II, and black tarsus (blt) on chromosome III. Tested by Hickey \& Craig (1966a,b), it did not show sex ratio distortion in male outcrosses, but its $\mathrm{X}$ chromosomes were found to be highly sensitive to $\mathrm{Y}$ chromosomes of other strains. Wood \& Ouda (1987) confirmed the sensitivity to T8 and demonstrated the presence of a sex-linked recessive factor $t$ (tolerance) which moderates the degree of sensitivity. A substrain (3M), selected in this laboratory, was homozygous for the three markers. Its sex ratio is normal.

Thursday island (Th.I) Based on a collection from an island off the north-east coast of Australia, this strain was supplied in 1986 by Dr I. Fanning, of the Institute of Medical Research, Brisbane, Australia. Its sex ratio is normal.

\section{Rearing technique}

All strains were kept at $28 \pm 1^{\circ} \mathrm{C}$ and $75 \pm 5$ per cent r.h. Eggs were hatched in 24 -h-old hay infusion, and the larvae fed on crushed dog biscuit. Larval density was regulated to approximately $1 \mathrm{~mL}^{-1}$, and the bowls were skimmed daily of excess surface debris and bacterial growth, using strips of cotton wool. Pupae were sexed according to size, and the emerging adults, in which sexes were checked, were provided with sucrose solution on a cotton wool pad. After 2 days, mated females were offered a blood meal from a 10-day-old mouse narcotized with 5 per cent Sagatal (May \& Baker Ltd). Eggs laid on filter paper cones inverted in water, were left moist for $48 \mathrm{~h}$ to allow embryonation, before the papers were dried.
T8 males were used to assess the sensitivity of the $\mathrm{X}$ chromosomes of females of Th.I (and also of the Syn and Syn (s) lines subsequently developed, see below).

\section{Mass-mating technique $(\mathrm{m})$}

The two strains to be mated were sexed and allowed to emerge in separate cages, where the sex status was confirmed. Males of T8 were transferred to a cage containing females of a colony whose $\mathrm{X}$ chromosomes were to be tested for sensitivity. The $F_{1}$ was mass intermated to give the $F_{2}$, which was assessed for sex ratio.

\section{Single-pair mating technique (s)}

A series of virgin male and a blood-fed virgin female mosquitoes, 3-5 days old, were pair-mated in 200 -mL containers supplied with sucrose and water. After $48 \mathrm{~h}$ each of the females was transferred into an individual netting-capped specimen tube with a filter paper cone dipping into the water at the bottom, as an oviposition site. The $F_{1}$ was mass inbred to give the $F_{2}$ which was assessed for sex ratio.

\section{Isolation of lines with sensitive $X$ chromosomes}

The breeding scheme, a modified and extended version of that described by Tesfamariam (1993), was as follows.

1 The strain from which the sensitive $X$ chromosome is to be isolated (in the present case Th.I) is inbred by single-pair mating to yield 100 progenies.

2 Each clutch of eggs is divided into two batches; one batch to be hatched and the other stored.

3 The females of each hatched batch are masscrossed with males of a strain with $M D Y$ Y chromosomes (in the present case T8).

4 The resultant $F_{1}$ progenies are separately inbred and their progenies $\left(\mathrm{F}_{2}\right)$ assessed for sex ratio.

5 The four most distorted $F_{2} s$ (per cent $q<20$ ) are identified and their corresponding stored eggs in (2) hatched.

6 Meanwhile, the four most highly distorted $F_{2} S$ from (5) are separately inbred up to the 10th generation to ascertain whether the sex ratio distortion will remain constant.

7 Females hatching from the stored eggs of (5) are in each of the four cases mated with nondistorting males, that is, a strain of genotype $M d$ (in the present case $3 \mathrm{M}$ ), to yield stock eggs of newly sensitive strains. 
8 The four progenies are inbred by single-pair mating (25 matings each).

9 Half the $F_{1}$ eggs of each of the 25 single-pair matings from each progeny of (8) are stored and the rest are hatched. Out of each hatched $F_{1}$, four females are randomly chosen and single-pair mated with males of the $M D$ strain. The next generation is inbred in each case, the sex ratio assessed in the following generation $\left(\mathrm{F}_{2}\right)$ and the most distorted lines noted.

10 The stored eggs corresponding to the most distorted $\mathrm{F}_{2} \mathrm{~s}$ are hatched and taken into further generations as the strains with the most sensitive $\mathrm{X}$ chromosomes.

\section{Results}

In order to identify and isolate Th.I X chromosomes most sensitive to the $\mathrm{Y}$ chromosome meiotic drive of T8 males, it was necessary to carry out steps 1,2 (part 1), 3 and 4 of the breeding scheme above. Females hatched from the stored eggs from each of the 100 single-pair progenies Th.IP $\times$ Th.I $\hat{\delta}$ were mass-crossed to $\mathrm{T} 8$ males (average of 20 males crossed to 20 females), the $F_{1} s$ interbred and the $F_{2} S$ investigated for sex ratio. Selected data from these $100 \mathrm{~F}_{2} \mathrm{~s}$ are given in Table 1. Included are the four most male-biased progenies (out of 73 showing significant male excess), four progenies showing $1: 1$ sex ratios (out of 21) and also four with female bias (out of six). Clearly, Th.I shows considerable variation in $\mathrm{X}$ sensitivity to the $\mathrm{T} 8 \mathrm{Y}$ chromosome. The overall percentage of females $\pm \mathrm{SE}$ was $34.49 \pm 1.38$ $(n=18852)$. The $\mathrm{X}$ polymorphism of Th.I is reflected in a highly significant heterogeneity $\chi^{2}$-value of $1023.57(P<0.001)$. The polymorphism included $\mathrm{X}$ chromosomes with capacity to drive against the T8 Y chromosome, yielding between 60 and 78 per cent $Q$.

Following steps 5 (part 1) and 6 of the breeding scheme, $F_{2}$ progenies Th.I $\times$ T $8 \hat{o}, 14,46,68$ and 75 (Table 1) were used to start colonies ThST14, ThST46, ThST68 and ThST75, to be maintained separately for 10 generations (Table 2). Sex ratio in these strains remained male-distorted with no evidence of regression to a normal sex ratio,

Table 1 Sex ratio in a sample of $F_{2}$ progenies from 100 mass crosses of T8 males to females drawn from 100 single-pair, Th.I $q \times$ Th.I $\$$, matings of Aedes aegypti

\begin{tabular}{|c|c|c|c|}
\hline Th.I $+\times \mathrm{T} 8 \hat{s}\left(\mathrm{~F}_{2}\right)$ & Total & $\%$ ㅇ & $\chi^{2} 1: 1$ \\
\hline 68 & 190 & 11.05 & $115.28 * * *$ \\
\hline 14 & 237 & 13.92 & $123.38 * * *$ \\
\hline 75 & 184 & 15.22 & $89.04^{* * *}$ \\
\hline 46 & 481 & 19.54 & $178.48 * * *$ \\
\hline - & - & - & - \\
\hline 25 & 135 & 47.41 & 0.36 \\
\hline 31 & 120 & 47.5 & 0.3 \\
\hline 16 & 147 & 50.34 & 0.01 \\
\hline 36 & 229 & 50.22 & 0 \\
\hline - & - & - & - \\
\hline 48 & 293 & 60.41 & $12.70^{* * *} \mathrm{x}$ \\
\hline 47 & 87 & 68.97 & $12.52^{* * *} \mathrm{x}$ \\
\hline 64 & 140 & 70 & $22.40^{* * *} \mathrm{x}$ \\
\hline 45 & 64 & 78.13 & $20.25 * * * x$ \\
\hline Total & 18852 & $34.49 \pm 1.38$ & \\
\hline
\end{tabular}

${ }^{*} P<0.05,{ }^{* *} P<0.01 ;{ }^{* * *} P<0.001$

$* * * x$, significant $\mathrm{X}$ chromosome drive.

Table 2 Sex ratios observed over 10 generations ( $F_{2}$ onwards) of the four strains of ThST $(14,46,68$ and 75$)$ of Aedes aegypti

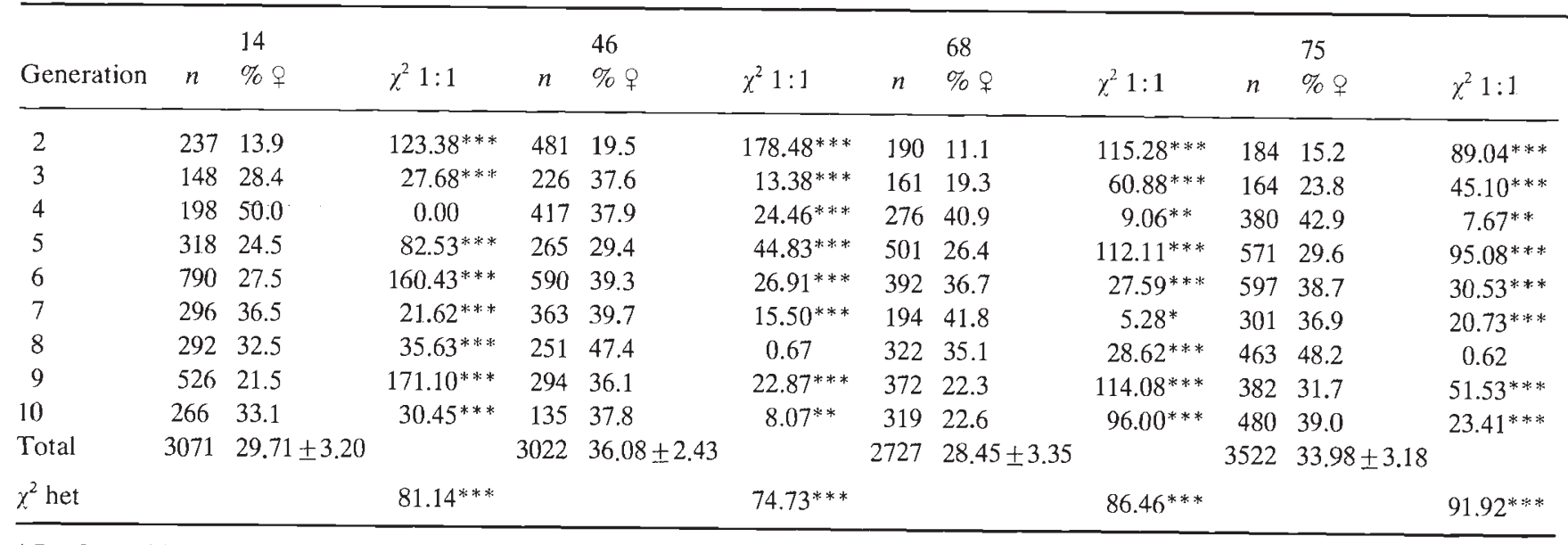

${ }^{*} P<0.05,{ }^{*} P<0.01 ;{ }^{* * *} P<0.001$. 
although there was a significant degree of heterogeneity between generations.

The stored eggs of three of the original $F_{1} s$ (Th.I $\times$ Th.I $\sigma^{\wedge}$ ) were now hatched and the $F_{2}$ females (14Th.I, 68Th.I, 75Th.I) were, in each case, mass-crossed to $3 \mathrm{M}$ males. The resultant progenies were referred to, respectively, as 14Syn, 68Syn and 75Syn (corresponding with steps 2 (part 2), 5 (part 2) and 7 of the breeding scheme). Insufficient hatch caused 46 Th.I to be abandoned.

The next procedure was the reselection to produce sensitivity to $\mathrm{T} 8 \mathrm{Y}$ chromosome drive in the absence of $D$, and used steps $8-10$ of the breeding scheme. Twenty-five single-pair matings were made within each mass progeny of the four Syn strains. Half the $F_{1}$ eggs of these 14Syn, 68Syn and 75Syn single pairs were kept and half hatched. Out of each hatching, 25 sets of four females were chosen at random, to be paired with each of $25 \mathrm{~T} 8$ males. The $\mathrm{F}_{1}$ progenies from these 100 single-pair crosses $(25$ sets of four) were inbred in each case to produce 25 sets of $F_{2} s$. In each of the $F_{2}$ sets, the one with the lowest proportion of females in all progenies was identified. These were set 4 of 14Syn, set 1 of 68Syn and set 5 of 75 Syn. The values are shown in Table 3: $16.34 \pm 1.06$ per cent $(n=989)$ for $14 \operatorname{Syn} / 4$, $12.20 \pm 0.82$ per cent $(n=1329)$ for $68 \mathrm{Syn} / 1$ and $13.63 \pm 1.18$ per cent $(n=586)$ for $75 \mathrm{Syn} / 5$. The stored eggs of $14 \mathrm{Syn}, 68 \mathrm{Syn}$ and $75 \mathrm{Syn}$, corresponding to these three progeny-sets, became strains $14 \operatorname{Syn}(\mathrm{s}), 68 \operatorname{Syn}(\mathrm{s})$ and $75 \operatorname{Syn}(\mathrm{s})$.

Using this technique, it was possible to maximize the chance of isolating highly sensitive strains

Table 3 Sex ratios (\% ㅇ) in three $\mathrm{F}_{2}$ progenies of Aedes aegypti derived from crosses $14 \operatorname{Syn} \uparrow \times \mathrm{T} 8 \hat{\sigma}, 68 \mathrm{Syn} \uparrow \times \mathrm{T} 8$ $\delta^{\star}$ and 75 Syn $q \times$ T8 $\$$. For further details see text

\begin{tabular}{lcrrrrr}
\hline $\begin{array}{l}\text { Syn } q \\
\text { parent }\end{array}$ & $\begin{array}{c}\text { Family } \\
\text { set }\end{array}$ & Total & $\% \%$ & $\chi^{2} 1: 1$ & $\begin{array}{c}\text { Mean } \\
\%\end{array}$ & SE \\
\hline 14 & $4 \mathrm{a}$ & 257 & 14.40 & $130.31^{* * *}$ & 16.34 & 1.06 \\
& $4 \mathrm{~b}$ & 463 & 20.52 & $160.97^{* * *}$ & & \\
& $4 \mathrm{c}$ & 134 & 11.94 & $77.64^{* * *}$ & & \\
68 & $4 \mathrm{~d}$ & 135 & 18.52 & $53.52^{* * *}$ & & \\
& $1 \mathrm{a}$ & 337 & 8.90 & $227.68^{* * *}$ & 12.20 & 0.82 \\
& $1 \mathrm{~b}$ & 397 & 12.59 & $222.19^{* * *}$ & & \\
& $1 \mathrm{c}$ & 325 & 13.23 & $175.76^{* * *}$ & & \\
75 & $1 \mathrm{~d}$ & 270 & 14.07 & $139.39^{* * *}$ & & \\
& $5 \mathrm{a}$ & 51 & 7.84 & $36.25^{* * *}$ & 13.63 & 1.18 \\
& $5 \mathrm{~b}$ & 190 & 13.16 & $103.16^{* * *}$ & & \\
& $5 \mathrm{c}$ & 122 & 15.57 & $57.84^{* * *}$ & & \\
& $5 \mathrm{~d}$ & 223 & 17.94 & $91.70^{* * *}$ & & \\
\hline
\end{tabular}

***P $<0.001$.

(C) The Genetical Society of Great Britain, Heredity, 79, 388-393. because the the T8 Y chromosome on which each strain was based had been tested (in each set of four single-pair crosses) against eight $\mathrm{X}$ chromosomes. The experiment provided further data on sex ratio (per cent $q \pm S E$ ) in the three Syn strains. When outcrossed against T8: 14Syn gave $26.92 \pm 1.02$ per cent 우 $(n=16582) ; 68$ Syn, $27.17 \pm 1.40$ per cent $ㅇ$ $(n=17603) ; \quad 75$ Syn $28.92 \pm 1.17$ per cent $q$ $(n=17873)$ (Table 4). The experiment also revealed something new about variation in $\mathrm{T} 8 \mathrm{Y}$ chromosomes. Among the $75 \mathrm{Y}$ chromosomes tested, there were five that showed no evidence of sex ratio distortion in any of the four families in the corresponding set (sampling eight $\mathrm{X}$ chromosomes). Overall, the data indicate the frequency of sensitive $\mathrm{X}$ chromosomes to be very high in the three strains. Minimum estimates are 89 out of 100 in 14Syn, 84 out of 100 in 68Syn and 87 out of 100 in 75Syn (mean 86.7 per cent), values obtained by counting the numbers of significantly distorted progeny sex ratios. The chance of a T8 Y chromosome becoming associated with eight resistant chromosomes is thus a maximum of $(1-0.867)^{8}$. It has to be concluded therefore that the $\mathrm{T} 8$ strain carries a proportion of $Y$ chromosomes that are incapable of driving against the Syn range of $\mathrm{X}$ chromosomes.

Total data on the three blocks of $\approx 25$ progeny-set test crosses of $14 \operatorname{Syn} q \times \mathrm{T} 8 \hat{\jmath}, 68 \mathrm{Syn} q \times \mathrm{T} 8 \hat{\jmath}$ and $75 \operatorname{Syn} 9 \times \mathrm{T} 8{ }^{\gamma}$ are compared in Table 4 with data from the original $100 \mathrm{Th} . \mathrm{I}$ ㅇ $\times \mathrm{T} 8 \widehat{0}$ crosses (abstracted from Table 1). As expected, each Syn strain showed greater sensitivity to $\mathrm{T} 8 \mathrm{Y}$ meiotic drive than Th.I, with significantly few females in the $F_{2}$. The correspondence with the original strains (Table 2) was close. $14 \mathrm{ThST}, 29.71 \pm 3.20 \mathrm{per}$ cent/ 14 Syn $\times$ T8,$\quad 26.92 \pm 1.02$ per cent; 68ThST, $28.45 \pm 3.35$ per cent $/ 68$ Syn $\times$ T8, $27.17 \pm 1.14$ per cent and 75ThST, 33.98 \pm 3.18 (coeff. var. 0.28)/ 75 Syn $\times \mathrm{T} 8,28.92 \pm 1.17$. The additional inbreeding and crossing to $3 \mathrm{M}$ had produced a slightly increased sensitivity in each case. The 14Syn(s), $68 \operatorname{Syn}(\mathrm{s})$ and $75 \operatorname{Syn}(\mathrm{s})$ strains carried the most sensitive $\mathrm{X}$ chromosomes we were able to isolate, although because they carried the $3 \mathrm{M} \mathrm{Y}$ chromosome, they showed no meiotic drive. To demonstrate meiotic drive, it was simply a matter of crossing females of one of these lines to $\mathrm{T} 8$ males. The $\mathrm{F}_{2}$ would show a sex ratio of $12-16$ per cent $q$ (Table $3)$.

\section{Discussion}

Single-pair matings have revealed a high degree of heterogeneity in response to the meiotic driving $M D$ 
Table 4 Sex ratio $\left(\%\right.$ ) in $\mathrm{F}_{2}$ Aedes aegypti from single-pair crosses Th.I $q \times \mathrm{T} 8$

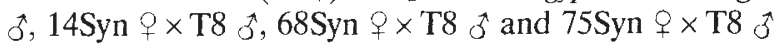

\begin{tabular}{|c|c|c|c|c|c|c|}
\hline q & $0^{\pi}$ & Total & $\begin{array}{l}\text { Total } \\
\% \text { \% }\end{array}$ & $\chi^{2} 1: 1$ & $\chi_{\text {het }}^{2}$ & $\begin{array}{c}\text { Mean } \%+ \pm \mathrm{SE} \\
\text { in single-pair progenies }\end{array}$ \\
\hline Th.I & T8 & 18852 & 33.87 & $1962.16^{* * *}$ & $1023.57^{* * *}$ & $34.49 \pm 1.38$ \\
\hline 14Syn & T8 & 16582 & 27.27 & $3434.71^{* * *}$ & $569.60^{* * *}$ & $26.92 \pm 1.02$ \\
\hline 68Syn & T8 & 17603 & 26.06 & $4224.28^{* * * *}$ & $713.67^{* *}$ & $27.17 \pm 1.14$ \\
\hline 75 Syn & T8 & 17873 & 30.28 & $2784.82^{* * *}$ & $746.61^{* * *}$ & $28.92 \pm 1.17$ \\
\hline
\end{tabular}

$* * *=P<0.001$.

$\mathrm{Y}$ chromosome. The variation is masked in mass crosses. The procedure for isolating sensitive lines from the Th.I strain, using T8, revealed not only the presence in Th.I of X chromosomes that were sensitive, but also others that were resistant, and a few with the capacity to drive against the $M D$ Y chromosome. The four selected strains (14ThST, 46ThST, 68ThST and 75ThST) showed a variable degree of sex ratio distortion over 10 generations with no tendency to regress to normal. The polymorphism that was maintained in these four strains, produced an overall proportion of females of $28-36$ per cent. Although not as high a degree of distortion as the 10-15 per cent $q$ observed in the generations that followed a cross Chipei $\times \mathrm{T} 8 \hat{0}$, reported by Wood \& Ouda (1987), it was greater than in the T8 strain itself (and its parent strain Trinidad) in which percentage of females varies between 40 and 43 per cent + (Wood, 1976; Wood \& Newton, 1991). It is clear, therefore, that polymorphism in $\mathrm{X}$ chromosome sensitivity to Trinidad-based meiotic drive can be established at various levels. The polymorphism in Trinidad itself has remained stable for more than 30 years (Wood \& Newton, 1991) under laboratory conditions in London, Pavia, Liverpool and Manchester.

Stable sex ratios in the four selected ThST strains probably point to the absence of modifiers of sensitivity recombining with the sex-determining locus (region), like the sex linked $t$ (tolerance) factor identified by Wood \& Ouda (1987) in TPM (= RED), the presence of which leads to gradual reversion towards a normal sex ratio over 5-12 generations. A similar phenomenon probably explains a population experiment carried out by Hickey \& Craig (1966b), in which sex ratio reverted to normal in a similar way. Hickey \& Craig (1966a) proposed that the generation of $m D$ haplotypes by recombination would give resistance to $M D$, although later evidence did not support this conclusion (Wood \& Ouda, 1987). In either case, however, separation of $M$ and $D$ would lead to the production of nondriving $\mathrm{Y}$ chromosomes. Thus, the absence of reversion to a normal sex ratio in the four ThST strains points either to: (i) the integrity of the $M D$ haplotype in these strains; or (ii) its selective advantage. The latter is more likely, bearing in mind the evidence from this study, indicating a minority of nondriving $\mathrm{Y}$ chromosomes in T8. It is supposed that these have most probably arisen by a recombination between $M$ and $D$, previously reported from an Accra strain (Newton et al., 1976).

Among the original Th.I $\times$ T 8 hybrid males, there was clearly more variability than in selected ThST strains, including the female-distorted sex ratios in some progenies. Genetic exchange between $\mathrm{X}$ and $\mathrm{Y}$ chromosomes is a possible explanation. With recombination certainly occurring outside the $M D$ region, on both arms of these isomorphic metacentric chromosomes, there is the mechanism for such exchange, even without assuming a separation between $M$ and $D$. Epistasis with autosomal genes affecting sex ratio is also a possibility, as found by Wood \& Ouda (1987). It is supposed that such interactions were reduced in the four selected ThST strains. The progressive increase in sensitivity to $M D$ that occurred as selection proceeded from Th.I to Syn, to Syn(s), proved the value of the scheme for isolating a sensitive strain. $F_{1}$ male hybrids produced from the reciprocal crosses between $\mathrm{T} 8 \% \times 68 \mathrm{Syn}_{O}^{*}$ (normal) and $68 \mathrm{Syn}+\times \mathrm{T} 8 \hat{0}$ (distortion) were investigated by electron microscopy for the effect of $M D$ on spermiogenesis. The results (Owusu-Daaku, 1994) indicate that a disruption of spermiogenesis lies behind the sex ratio distortion. The degree of male excess can be related directly to the extent to which sperms undergo premature senescence. We note here for the purposes of cross-reference that the samples for electron microscopy were taken from two reciprocal crosses: (i) $3 \mathrm{M}+\times \mathrm{T} 8 \hat{0}$ to yield $\mathrm{F}_{1}$ males designated 'Mutant' and $\mathrm{T} 8 \% \times 3 \mathrm{M} \hat{\sigma}$ to yield $F_{1}$ males designated 'Control 1'; and (ii) 68 Syn $1 \mathrm{a}^{\circ} \times \mathrm{T} 8{ }^{\wedge}$ to yield $\mathrm{F}_{1}$ males designated

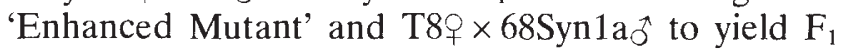


males designated 'Control 2'. It is reported how 'Mutant' spermiogenesis appeared little different from 'Control 1' in freshly emerged adults, but showed a much larger proportion of abnormal and degenerating spermatids and spermatozoa with multiple or lost organelles, 4 days later. The 'Enhanced Mutant' testes showed a greater degree of degeneration, even from the day of emergence (Owusu-Daaku, 1994). The natural process of spermatozoal senescence in 'Control' testes does not take place until day 8 postemergence. The sex ratios in the progeny of the brothers of the males from which these testes were taken were 'Mutant' 38.3 per cent 9 , 'Enhanced mutant' 8.9 per cent \%. The reciprocal crosses ('Control 1' and 'Control 2') gave 49.2 per cent $q$ and 51.2 per cent + , respectively.

On average the 68Syn $\mathrm{X}$ chromosomes showed a similar degree of sensitivity to drive to the wildcaught Chipei strain, although with less variance. Whereas some Chipeig $\times \mathrm{T} 8 \% \quad \mathrm{~F}_{2} \mathrm{~s}$ included no females at all (Wood, 1976), this extreme situation was not observed in any $68 \mathrm{Syn}+\times \mathrm{T} 80_{0} \mathrm{~F}_{2} \mathrm{~s}$. It has to be concluded that Th.I $\mathrm{X}$ chromosomes do not have quite the same potential for sensitivity as some of the Chipei X chromosomes.

Is there potential for using $\mathrm{Y}$ meiotic drive in practical vector control? Experiments, reviewed by Wood \& Newton (1991), investigated its potential for: (i) population suppression; (ii) population replacement; and (iii) genetic sexing. Positive achievements have been made in all three areas, although the phenomenon is clearly not ready for immediate exploitation. It is clear that the practical potential of Y meiotic drive could be enhanced by a greater knowledge of how it is controlled. It is hoped that the technique presented in this paper will be an aid towards making this possible.

\section{Acknowledgements}

We wish to acknowledge the financial support received from the Government of Ghana and the Lindeth Charitable Trust, UK, and also to thank Dr L. Munstermann and Dr I. Fanning (via Professor D. Molyneaux) for supplying strains of $A$. aegypti.

\section{References}

CRAIG, G. B., JR, HICKEY, W. A. AND VAN DE HEY, R. C. 1960. An inherited male producing factor in Aedes aegypti. Science, 132, 1887-1889.

HICKEY, W. A. AND CRAIG, G. B. JR 1966a. Genetic distortion of sex ratio in a mosquito, Aedes aegypti. Genetics, 53, 1177-1196.

HICKEY, W. A. AND CRAIG, G. B. JR 1966b. Distortion of sex ratio in populations of Aedes aegypti. Can. J. Genet. Cytol., 8, 260-278.

NEWTON, M. E., WOOD, R. J. AND SOUTHERN, D. 1. 1976. A cytogenetic analysis of meiotic drive in the mosquito, Aedes aegypti (L.). Genetica, 46, 297-318.

NEWTON, M. E., SOUTHERN, D. I. AND WOOD, R. J. 1978. Relative DNA content of normal and sex-ratio distorting spermatozoa of the mosquito, Aedes aegypti (L.). Chromosoma, 67, 253-261.

OWUSU-DAAKU, K. o. 1994. Spermiogenesis and Meiotic Drive in some Tropical Mosquitoes. Ph.D. Dissertation, University of Manchester, Manchester.

SUGUNA, J. G., WOOD, R. J., CURTIS, C. F., WHITELAW, A. AND KAZMI, s. J. 1977. Resistance to meiotic drive at the $M^{\mathrm{D}}$ locus in an Indian wild population of Aedes aegypti. Genet. Res., 29, 123-132.

tesfamariam, T. 1993. Analysis of the Sex Ratio and Related Biology in Laboratory Strains of Aedes aegypti (Linnaeus), Anopheles gambiae (Giles) and Anopheles arabiensis (Patton). Ph.D. Dissertation, University of Manchester, Manchester.

wooD, R. J. 1961. Biological and genetical studies on sex ratio in DDT and resistant strains of Aedes aegypti Linnaeus. Genet. Agr., 13, 287-307.

wOOD, R. J. 1968. Heterogeneity in the Trinidad DDT-resistant strain and the QS susceptible strain of Aedes aegypti L. Bull. World Health Org., 39, 639-645.

WOOD, R. J. 1976. Between-family variation in sex ratio in the Trinidad (T-30) strain of Aedes aegypti (L.) indicating differences in sensitivity to the meiotic drive gene $M^{\mathrm{D}}$. Genetica, 46, 345-361.

WOOD, R. J. AND NEWTON, M. E. 1977. Meiotic drive and sex ratio distortion in the mosquito Aedes aegypti. Proceedings 15th International Congress of Entomology, pp. 97-105.

WOOD, R. J. AND NEWTON, M. E. 1991. Sex-ratio distortion caused by meiotic drive in mosquitoes. Am. Nat., 137, 379-391.

WOOD, R. J. AND OUDA, N. A. 1987. The genetic basis of resistance and sensitivity to the meiotic drive gene $D$ in the mosquito Aedes aegypti L. Genetica, 72, 69-79. 